\title{
Primary safety and effectiveness feasibility study after surgical aortic valve replacement with a new generation bioprosthesis: one-year outcomes
}

\author{
Krzysztof Bartuś ${ }^{1}$, Radosław Litwinowicz ${ }^{1}$, Mariusz Kuśmierczyk², Agata Bilewska², Maciej Bochenek ${ }^{1}$, \\ Maciej Stąpór ${ }^{3}$, Sebastian Woźniak², Jacek Różański², Jerzy Sadowski ${ }^{1}$, Bogusław Kapelak ${ }^{1}$ \\ 'Department of Cardiovascular Surgery and Transplantology, Jagiellonian University, John Paul II Hospital, Krakow, Poland \\ ${ }^{2}$ The Cardinal Stefan Wyszynski Institute of Cardiology, Warsaw, Poland \\ ${ }^{3}$ John Paul II Hospital, Krakow, Poland
}

\begin{abstract}
A bs tra ct
Background: Structural valve deterioration (SVD) is a major obstacle to lifetime durability for bioprosthetic heart valves. A bioprosthetic valve created with RESILIA ${ }^{\text {TM }}$ tissue was designed to produce long-term resistance to SVD.

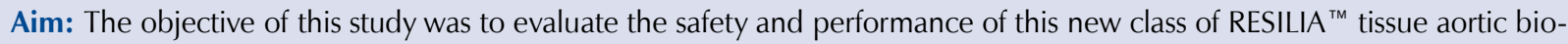
prosthesis.

Methods: A nonrandomised, prospective, multi-centre, single-arm, observational study was performed in 133 patients who underwent surgical aortic valve replacement between July 2011 and February 2013. Patients were assessed at 3-6 months and one year for haemodynamic performance, clinical outcomes, and functional improvement.

Results: The mean age was $65.3 \pm 13.5$ years, with 34 (25.6\%) of patients $<60$ years of age. Early ( $\leq 30$ day) and late ( $>30$ day) all-cause mortality rates were $2.3 \%(n=3)$ and $4.5 \%(n=6)$, respectively. Early events included thromboembolism in three (2.3\%) patients and major bleeding events requiring transfusion in six (4.5\%) patients. Late events included one endocarditis leading to explant. Mean gradients were reduced across all valve sizes and were maintained at one year of follow-up. The mean effective orifice area and effective orifice area index increased across all valve sizes postoperatively and were maintained at one year. The rates of paravalvular leak $(>2+)$ at 3-6 months and one-year follow-up were $0.7 \%$ and $0.7 \%$, respectively.

Conclusions: The new generation RESILIA ${ }^{T M}$ tissue aortic valve bioprosthesis demonstrated excellent haemodynamic performance and safety outcomes at one year of follow-up. Longer follow-up of these patients will provide further insight on long-term durability.
\end{abstract}

Key words: aortic valve replacement, RESILIA, new technology

Kardiol Pol 2018; 76, 3: 618-624

\section{INTRODUCTION}

In recent years, in the prosthetic heart valve market there has been great heterogeneity of valve sub-models, with different post-market surveillance and effectiveness [1]. Therefore, replacement of native heart valves with either bioprosthetic or mechanical substitutes requires patients and clinicians to weigh the impact on long-term quality of life and patient satisfaction associated with each [2]. Although durable, mechanical valves require the use of anticoagulants. In contrast, structural valve deterioration (SVD) is a major obstacle to durability for bioprosthetic heart valves, limiting their use particularly in younger patients [3]. The goal of combining the long-term durability of mechanical heart valves with the quality of life afforded by bioprosthetic heart valves has been aided by the development of advanced technologies aimed at improving the long-term durability of bioprosthetic heart valves.

A new class of bioprosthetic valve created with RESILIA ${ }^{\mathrm{TM}}$ tissue (Edwards Lifesciences LLC, Irvine, CA, USA) has been 
developed to produce long-term resistance to SVD and improve the durability of bioprosthetic heart valves. RESILIA ${ }^{\mathrm{TM}}$ tissue is made of bovine pericardium that undergoes two distinct treatments based on Edwards Integrity-Preservation $\left(\mathrm{EIP}^{\mathrm{TM}}\right)$ technology: stable capping, which permanently blocks calcium $\left(\mathrm{Ca}^{2+}\right)$ binding sites and glycerolisation, which protects and preserves tissue integrity. In preclinical in vitro and in vivo ovine and rabbit studies, RESILIA ${ }^{\mathrm{TM}}$ tissue demonstrated significantly less $\mathrm{Ca}^{2+}$ accumulation when compared with conventional tissue $[4,5]$. In addition, initial clinical data on the first 20 patients with severe aortic stenosis, who underwent isolated aortic valve replacement (AVR) with RESILIA ${ }^{\text {TM }}$ tissue valves, has demonstrated improved haemodynamic performance over baseline values, and durability and safety at up to one year of follow-up [6]. Herein we present our further results of all 133 patients who underwent AVR with RESILIA ${ }^{\text {TM }}$ in Poland. Our study present that the use of RESILIA ${ }^{\mathrm{TM}}$ tissue valves improves haemodynamic and clinical outcomes after surgical AVR. Furthermore, the present study encompassed a sizeable contingent of younger patients (aged $<60$ years), which should allow for the long-term follow-up of RESILIA ${ }^{\text {TM }}$ tissue valve performance.

\section{METHODS}

\section{Study design and population}

This was a prospective, non-randomised, un-controlled, two-centre, single-arm, observational study (Clinical Trial number: NCTO 1651052 - Clinical trial of Edwards Aortic Bioprosthesis Model 11000, https://clinicaltrials. gov/ct2/show/NCT01651052), which was designed to assess safety and haemodynamic performance. The study was designed by members of the Executive Committee on behalf of the study investigators in collaboration with the study sponsor, Edwards Lifesciences, LLC. The study protocol was reviewed and approved by the Ethics Committee and Polish Ministry of Health (CEBK). Inclusion and exclusion criteria were described in Table 1.

Patients were offered enrolment into the study by surgeons at individual investigational sites. The decision was based upon an indication for surgical AVR, an appropriate risk profile, and surgical preference for a bioprosthesis. Consenting patients were considered enrolled in the study after the surgeon visually inspected the aortic root, measured the aortic valve annulus, and determined that the study valve could be implanted. In each centre RESILIA ${ }^{\text {TM }}$ bioprostheses were implanted by two trained surgeons.

A complete one-year follow-up was achieved in 120 of 133 patients $(90.2 \%)$. Nine (6.8\%) patients had died and four $(3.0 \%)$ patients were not willing to participate further in the study and were lost to follow-up.

\section{Baseline characteristics}

Between July 2011 and February 2013, a total of 133 patients were enrolled in the study, of whom 99 (74.4\%) were over
Table 1. Inclusion and exclusion criteria

INCLUSION CRITERIA
Age 18 years or above
Written, informed consent prior to trial procedures
Aortic valve disease requiring a planned replacement
With or without concomitant bypass surgery
Willingness to attend all follow-up visits
EXCLUSION CRITERIA
Prior mitral, tricuspid, or pulmonic valve surgery
Need for multiple valve replacement/repair
Aneurysm of the aortic root and/or ascending aorta requiring
surgical intervention
Active endocarditis/myocarditis within three months of surgery
Renal insufficiency (serum creatinine $\geq 2.5$ mg/dL or end stage
renal disease requiring chronic dialysis)
MRI or CT scan confirmed stroke, cerebrovascular accident, or
transient ischaemic attack within six months (180 days) prior to
aortic valve replacement surgery
Acute myocardial infarction within 30 days
Left ventricular ejection fraction $\leq 30 \%$
CT — computed tomography; MRI — magnetic resonance imaging

60 years old, and who required replacement of diseased aortic valve.

Fifty-two (39.1\%) patients treated with the study valve had isolated aortic stenosis, 25 (18.8\%) had isolated aortic insufficiency, and 56 (42.1\%) had combined aortic valve dysfunction. Echocardiography examinations showed mitral valve defects not requiring interventions in 113 patients: in four (3.0\%) patients mild mitral valve stenosis and in 109 (81.9\%) mild mitral insufficiency. The patient distribution of the aetiology of aortic valve disease was as follows: 93 (69.9\%) subjects had degenerative valve disease, $24(18.0 \%)$ - dystrophic calcification, nine $(6.8 \%)$ - rheumatic heart disease, and $18(13.5 \%)$ had other aetiologies. Intraoperative examinations showed that two (1.5\%) patients had aortic regurgitation due to a previous episode of remote endocarditis. In both cases, there were no symptoms of infections and inflammatory markers were in the normal range. Detailed baseline patient characteristics are presented in Table 2.

\section{Study device and surgical procedure}

Surgical AVR was performed using the Edwards Aortic Bioprosthesis Model 11000A, a trileaflet bioprosthesis identical in design to the Carpentier-Edwards PERIMOUNT Magna Ease Aortic Valve (Model 3300TFX), except for the tissue technology of the leaflet material. The Model 11000A incorporates RESILIA $^{\text {TM }}$ tissue leaflets created with EIP ${ }^{\text {TM }}$ technology, which is an advanced tissue technology that preserves tissue integrity and is designed to produce consistent long-term resistance to SVD by stable capping, which permanently blocks calcium 
Table 2. Baseline characteristics

\begin{tabular}{|c|c|}
\hline Age [years]: & $65.3 \pm 13.5(22.0-88.0)$ \\
\hline$<50$ & $16(12.0 \%)$ \\
\hline $50-60$ & $18(13.5 \%)$ \\
\hline$>60$ & $99(74.4 \%)$ \\
\hline Female gender & $68(51.1 \%)$ \\
\hline \multicolumn{2}{|l|}{ Race: } \\
\hline Caucasian/white & $113(85.0 \%)$ \\
\hline Not available & $20(15.0 \%)$ \\
\hline \multicolumn{2}{|l|}{ Echocardiographic variables: } \\
\hline BMI $\left[\mathrm{kg} / \mathrm{m}^{2}\right]$ & $29.3 \pm 6.7(15.8-62.1)$ \\
\hline LVEF [\%] & $61.2 \pm 13.7$ \\
\hline \multicolumn{2}{|l|}{ New York Heart Association: } \\
\hline Class I & $28(21.1 \%)$ \\
\hline Class II & $61(45.9 \%)$ \\
\hline Class III & $42(31.6 \%)$ \\
\hline Class IV & $2(1.6 \%)$ \\
\hline \multicolumn{2}{|l|}{ Comorbidities: } \\
\hline Systemic hypertension & $105(78.9 \%)$ \\
\hline Coronary artery disease & $64(48.1 \%)$ \\
\hline Arrhythmia/conduction disturbance & $33(24.8 \%)$ \\
\hline Myocardial infarction & $10(7.5 \%)$ \\
\hline Cerebrovascular disease & $7(5.3 \%)$ \\
\hline Congestive heart failure & $3(2.3 \%)$ \\
\hline Pulmonary hypertension & $2(1.5 \%)$ \\
\hline History of rheumatic fever & $8(6.0 \%)$ \\
\hline Carotid artery disease & $6(4.5 \%)$ \\
\hline Obesity & $49(36.8 \%)$ \\
\hline Diabetes & $24(18.0 \%)$ \\
\hline Renal failure & $13(9.8 \%)$ \\
\hline Chronic pulmonary disease & $11(8.3 \%)$ \\
\hline Peripheral artery or vascular disease & $3(2.3 \%)$ \\
\hline History of smoking & $27(20.3 \%)$ \\
\hline Current smokers & $9(6.8 \%)$ \\
\hline
\end{tabular}

Data are shown as mean \pm standard deviation or number (percentage). $\mathrm{BMI}$ - body mass index; LVEF — left ventricular ejection fraction

$\left(\mathrm{Ca}^{2+}\right)$ binding sites $[4,5]$. The surgical approach and technique of implantation was at the discretion of the investigator per his/her routine surgical practice and performed via full or partial sternotomy using previously described techniques [6]. At the discretion of the investigator, bioprosthetic heart valve recipients should be maintained on anticoagulant therapy (except when contraindicated) during the initial healing stages after implant, 2-3 months in accordance with the American College of Cardiology/American Heart Association 2008 Guidelines for the Management of Patients with Valvular Heart Disease [7]. Anticoagulants should then be discontinued over a period of 10 days, except in those patients for whom ongoing anticoagulant treatment is indicated.

\section{Safety and performance endpoints}

Safety endpoints included the following: SVD, thromboembolism, all bleeding/haemorrhage, major bleeding/haemorrhage, all paravalvular leak (PVL), major PVL, non-structural valve dysfunction, endocarditis, haemolysis, all-cause mortality, study valve-related mortality, and explant. SVD included dysfunction or deterioration involving the operated valve (except infection or thrombosis).

Performance endpoints included clinically acceptable haemodynamic performance confirmed by the core lab evaluation of echocardiography, RadCore Labs Torrance, CA, USA.

\section{Data management}

As a study sponsor, Edwards Lifesciences managed the collection and monitoring of data. Data on adverse events and safety outcomes were reviewed and adjudicated by an independent Clinical Events Committee.

\section{Statistical analysis}

Summary statistics for continuous variables include the number of subjects with a value for the variable of interest as well as the mean and standard deviation, unless otherwise noted. Summary statistics for categorical variables include the number and percentage of subjects with a recorded value for the variable of interest. Early adverse events, defined as occurring within $\leq 30$ days of the index procedure, were reported as the number of events divided by the number of enrolled subjects. Linearised rates were used to summarise adverse events for the late ( $>30$ days) postoperative period. The linearised rates were calculated as the number of late events divided by the total number of late-subject years with one-sided upper 95\% confidence limit (CL). Percentages are calculated as the number of patients with an event divided by the total number of patients receiving the study valve. All data were based on a database lock date of March 31, 2015. Statistical analysis was undertaken using SAS Statistical software package version 7.0.

\section{RESULTS}

\section{Procedural outcomes}

There were 114 (85.7\%) patients who underwent isolated AVR, $16(12.0 \%)$ who underwent surgery for AVR plus coronary artery bypass grafting, and three (2.3\%) who were treated for AVR plus other concomitant procedures. Of the surgical approaches utilised, 117 (88.0\%) patients underwent full sternotomy and 16 (12.0\%) underwent a mini-upper sternotomy. Technical success was achieved in all 133 patients on the first attempt. Cross-clamp time and cardiopulmonary bypass time for isolated AVR cases averaged $61.7 \pm 14.4 \mathrm{~min}$ and $96.2 \pm 25.6 \mathrm{~min}$, respectively. The average length of stay for all 
Table 3. Safety outcomes

\begin{tabular}{|c|c|c|c|}
\hline Adverse event & $\begin{array}{l}\text { Early events }(\leq \mathbf{3 0} \text { days }) \\
\qquad n^{\mathrm{a}}, \mathrm{m}^{\mathrm{b}}(\mathrm{m} / \mathrm{N})\end{array}$ & $\begin{array}{l}\text { Late events (> } 30 \text { days) } \\
n^{\mathrm{c}}, \mathrm{m}^{\mathrm{b}} \text { (m/Late Pt-Yrs) }\end{array}$ & $95 \% \mathrm{CL}^{\mathrm{d}}$ \\
\hline Mortality & $3,3(2.3 \%)$ & $6,9(6.8 \%)$ & $45.8 \%$ \\
\hline Reoperation & $0,0(0.0 \%)$ & $1,1(0.7 \%)$ & $1.5 \%$ \\
\hline Explant ${ }^{e}$ & $0,0(0.0 \%)$ & $1,1(0.7 \%)$ & $1.5 \%$ \\
\hline Thromboembolism & $3,3(2.3 \%)$ & $1,1(0.7 \%)$ & $1.5 \%$ \\
\hline Major bleeding event requiring transfusion & $6,6(4.5 \%)$ & $0,0(0.0 \%)$ & $1.2 \%$ \\
\hline Paravalvular leak major & $1,1(0.7 \%)$ & $0,1(0.7 \%)$ & $1.5 \%$ \\
\hline Endocarditis & $0,0(0.0 \%)$ & $1,1(0.7 \%)$ & $1.5 \%$ \\
\hline Structural valve deterioration & $0,0(0.0 \%)$ & $0,0(0.0 \%)$ & $1.5 \%$ \\
\hline
\end{tabular}

${ }^{a} n-$ ' $n$ ' is the number of subjects who experienced the specific type of adverse events $\leq 30$ days.

${ }^{b} \mathrm{~m}-$ ' $\mathrm{m}$ ' is the number of specific adverse events observed.

' $n-$ ' $n$ ' is the number of subjects who experienced the specific type of adverse events $>30$ days.

d $95 \% \mathrm{CL}$ is the one-sided upper $95 \%$ confidence limit for the linearised rate.

explant due to endocarditis occurred in one patient.

Pt-Yrs — patient-years

patients was $9.7 \pm 5.0$ days, with an average of $2.2 \pm 2.4$ days in the intensive care unit (ICU) and $7.6 \pm 5.4$ days in the general ward.

Usually, if the increased surgical bleeding was reduced, oral warfarin was commenced within 24 to $48 \mathrm{~h}$ after the procedure, and international normalised ratio (INR) was maintained at a therapeutic range of 2.0-3.0 for up to three months. After three months, the further decision on continuation or discontinuation of anticoagulation treatment was at the discretion of the managing physicians.

\section{Safety outcomes}

Early primary safety ( $\leq 30$ days) and late ( $>30$ day) safety outcomes are presented in Table 3. Early events included all-cause mortality in three (2.3\%) patients, thromboembolism in three $(2.3 \%)$, including stroke in two patients and transient ischaemic attacks in one patient, and major bleeding events requiring transfusion in six $(4.5 \%)$. The cause of bleeding in four patients was anticoagulantion-related haemorrhage. INR values in these patients exceeded the therapeutic range. Two patients were re-opened for cardiac tamponade and two other patients for excessive bleeding (no surgical cause identified) within the first month ( $\leq 30$ days). These surgical interventions were not related to implanted bioprosthesis.

One valve was explanted due to endocarditis ( $>30$ days). Post-mortem revealed prosthesis valve thrombosis (PVT) in one case.

\section{Haemodynamic outcomes}

One case of PVL $(>2+)$ was observed at 3-6 months in a patient with a valve size of $23 \mathrm{~mm}$. Echocardiographic data for all subjects stratified by valve size are shown for baseline, 3-6 months, and one year of follow-up in Table 4. After im- plantation, there were no statistically significant differences in the effective orifice area (EOA), effective orifice area indexed to body surface area (EOAi), and mean pressure across all valve sizes post-operatively in 3-6 months of follow-up and one-year follow-up.

\section{Functional status}

New York Heart Association (NYHA) functional class improvement was noted in $69.3 \%$ of patients at 3-6 months of follow-up, whereas $28.3 \%$ of patients reported the same NYHA functional class as at baseline. At one year postoperatively, $95.1 \%$ of patients reported the same or improved NYHA functional class compared with baseline.

\section{DISCUSSION}

The RESILIA ${ }^{\mathrm{TM}}$ bioprosthetic heart valve was developed to produce consistent long-term resistance to SVD. Early and late clinical outcomes and haemodynamic performance of RESILIA $^{\mathrm{TM}}$ tissue valves were first studied in a series of 20 patients [6]. The current prospective, multicentre, single-arm study extends these previously published observations from 20 to 133 patients, including 34 young adults under the age of 60 years [6]. Data from the current study demonstrate that the haemodynamic performance of RESILIA ${ }^{\mathrm{TM}}$ tissue valves is acceptable and is similar to C-E Perimount valves [8], and C-E Perimount Magna Ease [9], with low rates of adverse events at one-year follow-up.

Echocardiographic evaluation of overall haemodynamic performance at 3-6 months and one year post-implant demonstrated a mean EOA of $1.8 \pm 0.6 \mathrm{~cm}^{2}$, an EOAi of $1.0 \pm 0.3$ and $0.9 \pm 0.3 \mathrm{~cm}^{2} / \mathrm{m}^{2}$, and a mean pressure gradient of $12.0 \pm 5.7 \mathrm{mmHg}$ and $13.9 \pm 6.1 \mathrm{mmHg}$; obtained post-operative haemodynamic parameters were during the 
Table 4. Echocardiographic data by valve size at follow-up

\begin{tabular}{|c|c|c|c|c|c|c|c|}
\hline Parameter & Follow-up & $\begin{array}{c}19 \mathrm{~mm} \\
(\mathrm{n}=12)\end{array}$ & $\begin{array}{c}21 \mathrm{~mm} \\
(\mathrm{n}=46)\end{array}$ & $\begin{array}{l}23 \mathrm{~mm} \\
(\mathrm{n}=41)\end{array}$ & $\begin{array}{c}25 \mathrm{~mm} \\
(\mathrm{n}=24)\end{array}$ & $\begin{array}{l}27 \mathrm{~mm} \\
(\mathrm{n}=10)\end{array}$ & $\begin{array}{c}\text { Total } \\
(n=133)\end{array}$ \\
\hline \multirow[t]{3}{*}{$\mathrm{EOA}\left[\mathrm{cm}^{2}\right]$} & Baseline & $0.8 \pm 0.2(12)$ & $0.8 \pm 0.3(45)$ & $0.9 \pm 0.5(40)$ & $1.5 \pm 1.3(23)$ & $1.8 \pm 1.1(10)$ & $1.0 \pm 0.8(130)$ \\
\hline & $3-6$ months & $1.4 \pm 0.4(12)$ & $1.7 \pm 0.4(43)$ & $1.9 \pm 0.4(37)$ & $2.1 \pm 0.7(24)$ & $2.3 \pm 0.5(10)$ & $1.8 \pm 0.5(126)$ \\
\hline & 1 year & $1.2 \pm 0.3(12)$ & $1.6 \pm 0.5(39)$ & $1.9 \pm 0.7(37)$ & $2.0 \pm 0.7(21)$ & $2.1 \pm 0.3(10)$ & $1.8 \pm 0.6(119)$ \\
\hline \multirow[t]{3}{*}{ EOAi $\left[\mathrm{cm}^{2} / \mathrm{m}^{2}\right]$} & Baseline & $0.4 \pm 0.1(12)$ & $0.4 \pm 0.2(37)$ & $0.5 \pm 0.2(30)$ & $0.8 \pm 0.7(21)$ & $0.9 \pm 0.6(9)$ & $0.6 \pm 0.4(109)$ \\
\hline & $3-6$ months & $0.8 \pm 0.3(12)$ & $1.0 \pm 0.3(35)$ & $1.0 \pm 0.3(29)$ & $1.1 \pm 0.4(22)$ & $1.1 \pm 0.3(9)$ & $1.0 \pm 0.3(107)$ \\
\hline & 1 year & $0.7 \pm 0.2(12)$ & $0.9 \pm 0.3(32)$ & $1.0 \pm 0.4(29)$ & $1.0 \pm 0.4(19)$ & $1.0 \pm 0.2(9)$ & $0.9 \pm 0.3(101)$ \\
\hline \multirow{3}{*}{$\begin{array}{l}\text { Mean gradient } \\
{[\mathrm{mmHg}]}\end{array}$} & Baseline & $49.2 \pm 16.4(12)$ & $54.0 \pm 20.8(46)$ & $50.6 \pm 21.6(41)$ & $43.5 \pm 24.0(24)$ & $38.0 \pm 22.6(10)$ & $49.4 \pm 21.7(133)$ \\
\hline & $3-6$ months & $20.0 \pm 11.1(12)$ & $12.0 \pm 4.6(43)$ & $11.1 \pm 3.9(39)$ & $10.8 \pm 3.5(24)$ & $8.8 \pm 3.5(10)$ & $12.0 \pm 5.7(128)$ \\
\hline & 1 Year & $21.7 \pm 9.5(12)$ & $14.2 \pm 4.9(40)$ & $12.0 \pm 4.3(37)$ & $13.8 \pm 3.5(21)$ & $11.1 \pm 4.5(10)$ & $13.9 \pm 6.1(120)$ \\
\hline
\end{tabular}

Data are shown as mean \pm standard deviation and (number). EOA — effective orifice area; EOAi - effective orifice area indexed to body surface area

whole follow-up period. The rate of moderate or severe PVL was $0.7 \%$ and $0.0 \%$, respectively. Furthermore, improvement or no change in NYHA functional class was observed in $>95.1 \%$ of patients at one year of follow-up.

Currently available heart valve substitutes are either mechanical or bioprosthetic; however, neither option provides an ideal substitute for the native heart valve [10]. Mechanical valves, which are usually recommended for younger patients, provide superior long-term durability compared with bioprosthetic valves, but require strict anticoagulation prophylaxis, which increases the risk of major bleeding. On the other hand, bioprosthetic valves are a reasonable option for patients who wish to avoid long-term anticoagulation. In patients with surgical aortic bioprostheses, the use of low-dose aspirin is now favoured as an alternative to postoperative anticoagulant therapy [11]. However, bioprosthetic valves are prone to structural degradation over time $[8,12]$. Underlying both treatment options is patient prognosis, which depends in part on durability, valve haemodynamic performance, potential risks and complications, and the potential need for chronic anticoagulation therapy $[10,13]$.

In our study, there was one $(0.7 \%)$ case of PVT discovered in post-mortem examination. The incidence of PVT observed in bioprosthetic heart valve is around 1.2\% [11]. The type of bioprosthesis also appears to influence the risk of PVT; thus, the risk of thrombosis is higher with stented than with stentless bioprostheses, and the risk of PVT is highest in the first three months after implantation [11, 14]. Therefore, we suggest that the prevalence of PVT after RESILIA ${ }^{\mathrm{TM}}$ tissue valve implantation is acceptable.

The average length of stay on ICU was 2.2 days, and 7.6 days in the general ward. The discharge of patients from the ICU to the postoperative ward was determined by the patient's health status assessed by the Therapeutic Intervention Scoring System (score between 0 and 19 points; TISS-28) of cardiac surgical postoperative intensive care and by the clinical judgment of the physician discharging the patient from the ICU. No fast-track or early extubation anaesthetic techniques were used [15]. Compared with other bioprosthesis studies [16], RESILIA $^{\mathrm{TM}}$ valves demonstrated a slightly lower ICU and overall length of hospital stay.

The primary mechanism of failure of the bioprosthetic heart valve implantation is SVD, a process in which biologically-derived valvular leaflet tissue undergoes calcification over time, leading to stiffening and tearing [3]. Risk factors associated with the incidence of SVD include patient age at the time of implant, arterial hypertension, diabetes, cigarette smoking, hypercholesterolaemia, and chronic renal failure [17]. Although numerous cellular and molecular processes are thought to contribute to the calcification process, residual phospholipid and aldehyde moieties in processed bioprosthetic valve leaflets are important contributors to the formation of calcium phosphate crystals [18, 19].

Additional factors that affect the rate of calcification are: the size of the implanted bioprosthesis, whether the patient experiences Patient-Prosthesis Mismatch (PPM), and the amount of mechanical stress the valve experiences in vivo $[20,21]$. Consequently, the use of systemically administered pharmacological agents or localised treatment strategies utilising anti-calcification agents or tissue treatment approaches have been investigated as potential inhibitors of calcification [22, 23]. To this end, RESILIA ${ }^{\mathrm{TM}}$ tissue valves combine two features that are unique: stable capping that permanently blocks $\mathrm{Ca}^{2+}$ binding sites, and glycerolisation that preserves tissue integrity by displacing the water in the pericardial tissue with glycerol [24].

Preclinical in vitro and in vivo studies of RESILIA ${ }^{\text {TM }}$ tissue bioprosthesis have been encouraging. Valve function and durability have been evaluated in a prospective, randomised study involving juvenile sheep, where RESILIA ${ }^{\mathrm{TM}}$ mitral valves were 
compared with PERIMOUNT valves, which have demonstrated a 25-year durability [5, 25]. At eight months of follow-up, RESILIA ${ }^{\text {TM }}$ mitral valves had significantly less $\mathrm{Ca}^{2+}$ content than PERIMOUNT valves, as confirmed by radiographic and histological analyses $(1.9 \pm 0.3 \mu \mathrm{g} / \mathrm{mg}$ vs. $6.8 \pm 1.6 \mu \mathrm{g} / \mathrm{mg}$, $\mathrm{p}=0.002$ ) [5]. Similarly, in a rabbit model in which tissue discs were implanted intramuscularly, there was significantly lower $\mathrm{Ca}^{2+}$ content at 60 days in RESILIA ${ }^{\text {TM }}$ tissue compared with bovine tissue treated with XenoLogicX [4, 26]. Overall, these results from in vitro and in vivo studies support the view that RESILIA ${ }^{\mathrm{TM}}$ bioprostheses show significantly less $\mathrm{Ca}^{2+}$ accumulation compared with conventional bioprostheses. For patients reaching the one-year follow-up points in our study, no SVD was observed in any patient.

When compared with other valves evaluated at similar follow-up periods, the haemodynamic performance of the RESILIA $^{\text {TM }}$ tissue valve was consistent with outcomes from other studies involving Carpentier-Edwards valves [27].

In a subsequent 2011 report, Mosaic valves demonstrated a one-year overall mean pressure gradient and EOA of $17.1 \pm 8.2 \mathrm{mmHg}$ and $1.69 \pm 0.40 \mathrm{~cm}^{2}$, respectively [28] Compared with these studies, RESILIA ${ }^{\mathrm{TM}}$ valves demonstrated a numerically lower overall mean pressure gradient and larger EOA, $13.9 \pm 6.1 \mathrm{mmHg}$ and $1.8 \pm 0.6 \mathrm{~cm}^{2}$, respectively. Moreover, the Epic bioprosthetic valve at one year demonstrated a mean pressure gradient of $15.3 \pm 6.5 \mathrm{mmHg}$ and EOAi of $0.67 \pm 0.2 \mathrm{~cm}^{2} / \mathrm{m}^{2}$, again suggesting superiority of the RESILIA ${ }^{\text {TM }}$ valve with a one-year EOAi of mean $0.9 \pm 0.3 \mathrm{~cm}^{2} / \mathrm{m}^{2}[16]$. However, at one year the EOAi for a 19$\mathrm{mm}$ valve is noted to be $0.7 \pm 0.2(\mathrm{n}=12)$. This may be due to the small number of patients, and physical characteristics (small annulus in a large patient) may have played a role. When compared with the results of a recent study by Wendt et al. [9], which reported the mean pressure gradients of the Trifecta, Magna, and Magna Ease bioprosthetic valves, the RESILIA $^{\text {TM }}$ values implanted in the present study appeared to be comparable. Finally, in patients with a small aortic annulus, a population at higher risk for prosthesis-patient mismatch, at one year the RESILIA ${ }^{\mathrm{TM}}$ demonstrated a mean EOAi of $0.7 \pm 0.2(\mathrm{n}=12)$ for the $19-\mathrm{mm}$ valve, with no incidence of severe PPM, which is larger than the reported EOAi for the $19-\mathrm{mm}$ Mosaic Ultra valve $\left(0.66 \pm 0.15 \mathrm{~cm}^{2} / \mathrm{m}^{2}\right.$ at $6.5 \pm 4.0$ months of follow-up) [29]. For the overall group, the EOAi was $0.9 \pm 0.3$ (101) with no incidence of severe PPM.

Finally, when selecting an appropriate bioprosthetic valve, the age of the patient is the most important predictor of SVD. Bourguignon et al. [30], reported that patients receiving a PERIMOUNT aortic valve experienced markedly different rates of reoperation for SVD depending on their age at the time of the index procedure. Indeed, a 50-year-old patient had a $20 \%$ probability of reoperation after 15 years, whereas a 70 -year-old patient had only a $5 \%$ probability of reoperation. Similarly, Johnston et al. [20] confirmed the relationship between the risk of reoperation for SVD and patient age at implant. However, when comparing the survival of patients receiving mechanical vs. bioprosthetic valves, Chiang et al. [2] have recently reported no difference in 15-year survival or stroke in a retrospective analysis of 4253 propensity-matched patients aged 50-69 years, who underwent AVR. Also, patients in the bioprosthetic valve group had a greater likelihood of reoperation but a lower likelihood of major bleeding. Thus, the authors concluded that the lack of a significant difference in mortality suggests bioprostheses may be a reasonable alternative to mechanical valves in younger patients.

\section{Limitations of the study}

This study was single-arm with non-consecutive enrolment, and there was no active comparator group. Hence, selection bias cannot be excluded. Additional randomised controlled studies will be necessary in the future to compare the RESILIA ${ }^{\text {TM }}$ with other valves. The number of patients who received 19-mm valves in this series is quite small and hence it will be difficult to assess the incidence of severe PPM. Also, assumptions of durability are limited because this study reports the safety and efficacy outcomes at one year.

\section{CONCLUSIONS}

Structural valve deterioration is a major obstacle to lifetime durability for bioprosthetic heart valves, particularly in younger patients. In this report on 133 patients, which includes 34 young adults under the age of 60 years, a new generation RESILIA ${ }^{\text {TM }}$ tissue aortic valve bioprosthesis demonstrated excellent haemodynamic performance and safety outcomes at one-year follow-up. Longer follow-up of these patients will provide further insight on the long-term durability of RESILIA ${ }^{\text {TM }}$ tissue bioprosthetic heart valves. Patients from the multicentre COMMENCE trial will be followed and assessed after Edwards Aortic Bioprosthesis Model 11000 with RESILIA ${ }^{\text {TM }}$ tissue implantation for up to five years.

Funding: This study was performed with financial and technical support (medical devices — valves) from Edwards Lifesciences Inc. (Irvine, CA, USA) to both Institutions.

\section{Conflict of interest: none declared}

\section{References}

1. Hickey GL, Bridgewater B, Grant SW, et al. National Registry Data and Record Linkage to Inform Postmarket Surveillance of Prosthetic Aortic Valve Models Over 15 Years. JAMA Intern Med. 2017; 177(1): 79-86, doi: 10.1001/jamainternmed.2016.6936, indexed in Pubmed: 27820610.

2. Chiang YP, Chikwe J, Moskowitz AJ, et al. Survival and long-term outcomes following bioprosthetic vs mechanical aortic valve replacement in patients aged 50 to 69 years. JAMA. 2014; 312(13): 1323-1329, doi: 10.1001/jama.2014.12679, indexed in Pubmed: 25268439

3. Grunkemeier GL, Furnary AP, Wu Y, et al. Durability of pericardial versus porcine bioprosthetic heart valves. J Thorac Cardiovasc 
Surg. 2012; 144(6): 1381-1386, doi: 10.1016/j.jtcvs.2012.08.060, indexed in Pubmed: 23010581.

4. De La, Wright GA, Olin JM, et al. Advanced Integrity Preservation Technology Reduces Bioprosthesis Calcification While Preserving Performance and Safety. J Heart Valve Dis. 2015; 24(1): 101-109, indexed in Pubmed: 26182627.

5. Flameng W, Hermans H, Verbeken E, et al. A randomized assessment of an advanced tissue preservation technology in the juvenile sheep model. J Thorac Cardiovasc Surg. 2015; 149(1): 340-345, doi: 10.1016/j.jtcvs.2014.09.062, indexed in Pubmed: 25439467.

6. Sadowski J, Bartuś K, Kapelak B, et al. Aortic valve replacement with a novel anti-calcification technology platform. Kardiol Pol. 2015; 73(5): 317-322, doi: 10.5603/KP.a2014.0214, indexed in Pubmed: 25371311.

7. Bonow RO, Carabello BA, Chatterjee K, et al. American College of Cardiology/American Heart Association Task Force on Practice Guidelines. 2008 focused update incorporated into the ACC/AHA 2006 guidelines for the management of patients with valvular heart disease: a report of the American College of Cardiology/American Heart Association Task Force on Practice Guidelines (Writing Committee to revise the 1998 guidelines for the management of patients with valvular heart disease). Endorsed by the Society of Cardiovascular Anesthesiologists, Society for Cardiovascular Angiography and Interventions, and Society of Thoracic Surgeons. J Am Coll Cardiol. 2008; 52(13): e1-e142, doi: 10.1016/j.jacc.2008.05.007, indexed in Pubmed: 18848134.

8. Nishida T, Sonoda H, Oishi Y, et al. Long-term results of aortic valve replacement with mechanical prosthesis or carpentier-edwards perimount bioprosthesis in Japanese patients according to age. Circ J. 2014; 78(11): 2688-2695, doi: 10.1253/circj.cj-14-0466, indexed in Pubmed: 25262964.

9. Wendt D, Thielmann M, Plicht B, et al. The new St Jude Trifecta versus Carpentier-Edwards Perimount Magna and Magna Ease aortic bioprosthesis: is there a hemodynamic superiority? J Thorac Cardiovasc Surg. 2014; 147(5): 1553-1560, doi: 10.1016/j. jtcvs.2013.05.045, indexed in Pubmed:23870159.

10. Wu Y, Butchart EG, Borer JS, et al. Clinical evaluation of new heart valve prostheses: update of objective performance criteria. Ann Thorac Surg. 2014; 98(5): 1865-1874, doi: 10.1016/j.athoracsur.2014.05.006, indexed in Pubmed: 25258160.

11. Nishimura RA, Otto CM, Bonow RO, et al. ACC/AHA Task Force Members. 2014 AHA/ACC Guideline for the Management of Patients With Valvular Heart Disease: executive summary: a report of the American College of Cardiology/American Heart Association Task Force on Practice Guidelines. Circulation. 2014; 129(23): 2440-2492, doi: 10.1161/CIR.0000000000000029, indexed in Pubmed: 24589852.

12. Vesey JM, Otto CM. Complications of prosthetic heart valves. Curr Cardiol Rep. 2004; 6(2): 106-111, doi: 10.1007/s11886-0040007-x, indexed in Pubmed: 14759353.

13. Blauwet LA, Miller FA. Echocardiographic assessment of prosthetic heart valves. Prog Cardiovasc Dis. 2014; 57(1): 100-110, doi:10.1016/j.pcad.2014.05.001, indexed in Pubmed: 25081405.

14. Dangas GD, Weitz JI, Giustino G, et al. Prosthetic Heart Valve Thrombosis. J Am Coll Cardiol. 2016; 68(24): 2670-2689, doi: 10.1016/j.jacc.2016.09.958, indexed in Pubmed: 27978952.

15. Litwinowicz R, Bartus K, Drwila R, et al. In-hospital mortality in cardiac surgery patients after readmission to the intensive care unit: a single-center experience with 10,992 patients. J Cardiothorac Vasc Anesth. 2015; 29(3): 570-575, doi: 10.1053/j. jvca.2015.01.029, indexed in Pubmed: 26009285.

16. Bobiarski J, Newcomb AE, Elhenawy AM, et al. One-year hemodynamic comparison of Perimount Magna with St Jude Epic aortic bioprostheses. Arch Med Sci. 2013; 9(3): 445-451, doi: 10.5114/aoms.2013.35479, indexed in Pubmed: 23847665.
17. Mohammadi S, Tchana-Sato V, Kalavrouziotis D, et al. Long-term clinical and echocardiographic follow-up of the Freestyle stentless aortic bioprosthesis. Circulation. 2012; 126(11 Suppl 1): S198-S204, doi: 10.1161/CIRCULATIONAHA.111.084806, indexed in Pubmed: 22965983.

18. Perrotta I, Davoli M. Collagen mineralization in human aortic valve stenosis: a field emission scanning electron microscopy and energy dispersive spectroscopy analysis. Ultrastruct Pathol. 2014; 38(4): 281-284, doi: 10.3109/01913123.2014.901468, indexed in Pubmed: 24833324

19. Schoen FJ, Levy RJ. Calcification of tissue heart valve substitutes: progress toward understanding and prevention. Ann Thorac Surg. 2005; 79(3): 1072-1080, doi: 10.1016/j.athoracsur.2004.06.033, indexed in Pubmed: 15734452.

20. Johnston DR, Soltesz EG, Vakil N, et al. Long-term durability of bioprosthetic aortic valves: implications from 12,569 implants. Ann Thorac Surg. 2015; 99(4): 1239-1247, doi: 10.1016/j. athoracsur.2014.10.070, indexed in Pubmed: 25662439.

21. Urso S, Calderón P, Sadaba R, et al. Patient-prosthesis mismatch in patients undergoing bioprosthetic aortic valve implantation increases risk of reoperation for structural valve deterioration. J Card Surg. 2014; 29(4): 439-444, doi: 10.1111/jocs.12345, indexed in Pubmed: 24773571.

22. Chen W, Schoen FJ, Levy RJ. Mechanism of efficacy of 2-amino oleic acid for inhibition of calcification of glutaraldehyde-pretreated porcine bioprosthetic heart valves. Circulation. 1994; 90(1): 323-329, doi: 10.1161/01.cir.90.1.323, indexed in Pubmed: 8026014.

23. Vyavahare N, Hirsch D, Lerner E, et al. Prevention of bioprosthetic heart valve calcification by ethanol preincubation. Efficacy and mechanisms. Circulation. 1997; 95(2): 479-488, doi: 10.1161/01. cir.95.2.479, indexed in Pubmed: 9008467.

24. Tanzer ML. Intermolecular cross-links in reconstituted collagen fibrils. Evidence for the nature of the covalent bonds. J Biol Chem. 1968; 243(15): 4045-4054, indexed in Pubmed: 5666947.

25. Bourguignon T, Bouquiaux-Stablo AL, Loardi C, et al. Very late outcomes for mitral valve replacement with the Carpentier-Edwards pericardial bioprosthesis: 25-year follow-up of 450 implantations. J Thorac Cardiovasc Surg. 2014; 148(5): 2004-2011.e1, doi: 10.1016/j.jtcvs.2014.02.050, indexed in Pubmed: 24667021

26. Wright GA, Faught JM, Olin JM. Assessing anticalcification treatments in bioprosthetic tissue by using the New Zealand rabbit intramuscular model. Comp Med. 2009; 59(3): 266-271, indexed in Pubmed: 19619417.

27. Dalmau MJ, María González-Santos J, López-Rodríguez J, et al. One year hemodynamic performance of the Perimount Magna pericardial xenograft and the Medtronic Mosaic bioprosthesis in the aortic position: a prospective randomized study. Interact Cardiovasc Thorac Surg. 2007; 6(3): 345-349, doi:10.1510/icvts.2006.144196, indexed in Pubmed: 17669862.

28. Dalmau MJ, González-Santos JM, Blázquez JA, et al. Hemodynamic performance of the Medtronic Mosaic and Perimount Magna aortic bioprostheses: five-year results of a prospectively randomized study. Eur J Cardiothorac Surg. 2011; 39(6): 844-52; discussion 852, doi: 10.1016/j.ejcts.2010.11.015, indexed in Pubmed: 21193320.

29. Okamura H, Yamaguchi A, Yoshizaki T, et al. Clinical outcomes and hemodynamics of the 19-mm Perimount Magna bioprosthesis in an aortic position: comparison with the 19-mm Medtronic Mosaic Ultra Valve. Circ J. 2012; 76(1): 102-108, doi: 10.1253/circj.cj-11-0728, indexed in Pubmed: 22094910.

30. Bourguignon T, Bouquiaux-Stablo AL, Candolfi P, et al. Very long-term outcomes of the Carpentier-Edwards Perimount valve in aortic position. Ann Thorac Surg. 2015; 99(3): 831-837, doi: 10.1016/j.athoracsur.2014.09.030, indexed in Pubmed: 25583467.

Cite this article as: Bartuś K, Litwinowicz R, Kuśmierczyk M, et al. Primary safety and effectiveness feasibility study after surgical aortic valve replacement with a new generation bioprosthesis: one-year outcomes. Kardiol Pol. 2018; 76(3): 618-624, doi: 10.5603/KP.a2017.0262. 